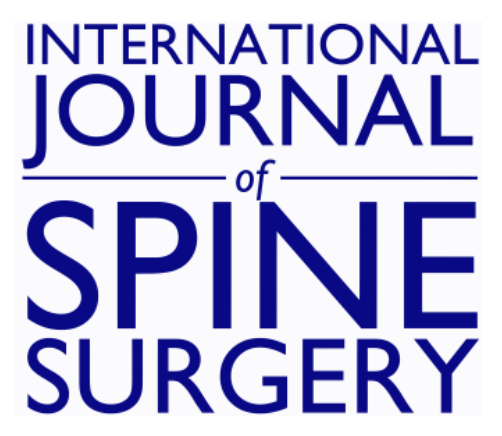

\title{
Metastatic Paraganglioma of the Spine With SDHB Mutation: Case Report and Review of the Literature
}

Rashad Jabarkheel, Arjun V. Pendharkar, Jonathan L. Lavezo, Justin Annes, Kaniksha Desai, Hannes Vogel and Atman M. Desai

Int J Spine Surg 2021, 14 (s4) S37-S45

doi: https://doi.org/10.14444/7163

http://ijssurgery.com/content/14/s4/S37

This information is current as of April 26, 2023.

Email Alerts Receive free email-alerts when new articles cite this article. Sign up at:

http://ijssurgery.com/alerts

The International Journal of Spine Surgery

2397 Waterbury Circle, Suite 1,

Aurora, IL 60504, Phone: +1-630-375-1432 


\title{
Metastatic Paraganglioma of the Spine With $S D H B$ Mutation: Case Report and Review of the Literature
}

\author{
RASHAD JABARKHEEL, MD, ${ }^{1}$ ARJUN V. PENDHARKAR, MD, ${ }^{1}$ JONATHAN L. LAVEZO, MD ${ }^{2}$ \\ JUSTIN ANNES, MD, PHD,${ }^{3}$ KANIKSHA DESAI, MD,${ }^{3}$ HANNES VOGEL, MD, ${ }^{2}$ ATMAN M. DESAI, MD ${ }^{1}$ \\ ${ }^{1}$ Department of Neurosurgery, ${ }^{2}$ Department of Pathology, ${ }^{3}$ Department of Medicine, Division of Endocrinology and Endocrine Tumor Program, Stanford \\ University School of Medicine, Stanford, California
}

\begin{abstract}
Background: Paragangliomas (PGLs) are rare neuroendocrine tumors that can arise from any autonomic ganglion of the body. Most PGLs do not metastasize. Here, we present a rare case of metastatic PGL of the spine in a patient with a germline pathogenic succinate dehydrogenase subunit B $(S D H B)$ mutation.

Methods: In addition to a case report we provide a literature review of metastatic spinal PGL to highlight the importance of genetic testing and long-term surveillance of these patients.

Results: A 45-year-old woman with history of spinal nerve root PGL, 17 years prior, presented with back pain of several months' duration. Imaging revealed multilevel lytic lesions throughout the cervical, thoracic, and lumbar spine as well as involvement of the right mandibular condyle and clavicle. Percutaneous biopsy of the L1 spinal lesion confirmed metastatic PGL and the patient underwent posterior tumor resection and instrumented fusion of T7-T11. Postoperatively the patient was found to have a pathogenic $S D H B$ deletion.

Conclusions: Patients with $S D H x$ mutation, particularly $S D H B$, have increased risk of developing metastatic PGLs. Consequently, these individuals require long-term surveillance given the risk for developing new tumors or disease recurrence, even years to decades after primary tumor resection. Surgical management of spinal metastatic PGL involves correcting spinal instability, minimizing tumor burden, and alleviating epidural cord compression. In patients with metastatic PGL of the spine, genetic testing should be considered.
\end{abstract}

Tumors

Keywords: paraganglioma, $S D H B$, spine metastasis

\section{INTRODUCTION}

Paragangliomas (PGLs) are rare neuroendocrine tumors that can develop anywhere along the sympathetic and parasympathetic ganglia of the body with an estimated prevalence of 0.2 to 1 per $100,000{ }^{1,2}$ When PGLs arise from chromaffin cells they frequently overproduce catecholamines. PGLs arising from adrenal chromaffin cells are commonly known as pheochromocytomas and account for $80 \%-85 \%$ of chromaffin cell PGLs. ${ }^{3}$ Extra-adrenal PGLs are less frequent, are primarily found along the parasympathetic ganglia of the head and neck, and are more likely to be biochemically silent., ${ }^{4,5}$ Extra-adrenal PGLs generally present between ages 40 and 50 with symptoms of mass effect specific to their location of origin. ${ }^{5-7}$

Most PGLs do not metastasize, with only $10 \%-$ $17 \%$ ultimately being metastatic, although extraadrenal PGLs are thought to have greater metastatic potential. ${ }^{8,9}$ Diagnosis of metastatic PGL is difficult as there are no reliable cellular or molecular markers of metastatic disease, and thus progression is necessary for diagnosis. ${ }^{8,10}$ Given the rarity of metastatic disease, there is a relative paucity of literature on metastatic extra-adrenal PGL, especially for spinal metastasis. ${ }^{4,10-14}$ Here, we present a report of a patient with metastatic extra-adrenal PGL of the spine presenting 27 years after resection of primary spinal nerve root PGL who was found to have a germline succinate dehydrogenase subunit B $(S D H B)$ mutation.

\section{CASE PRESENTATION}

A 45-year-old woman with history of a large $(>8$ cm) spinal nerve root PGL, status postresection 27 years prior at an outside hospital, with a recurrence in the right tibia, status postresection 6 years prior also at an outside hospital, presented for care at our institution with severe thoracic back pain radiating around the rib cage for several months' duration, which was worse with movement. She endorsed feeling 

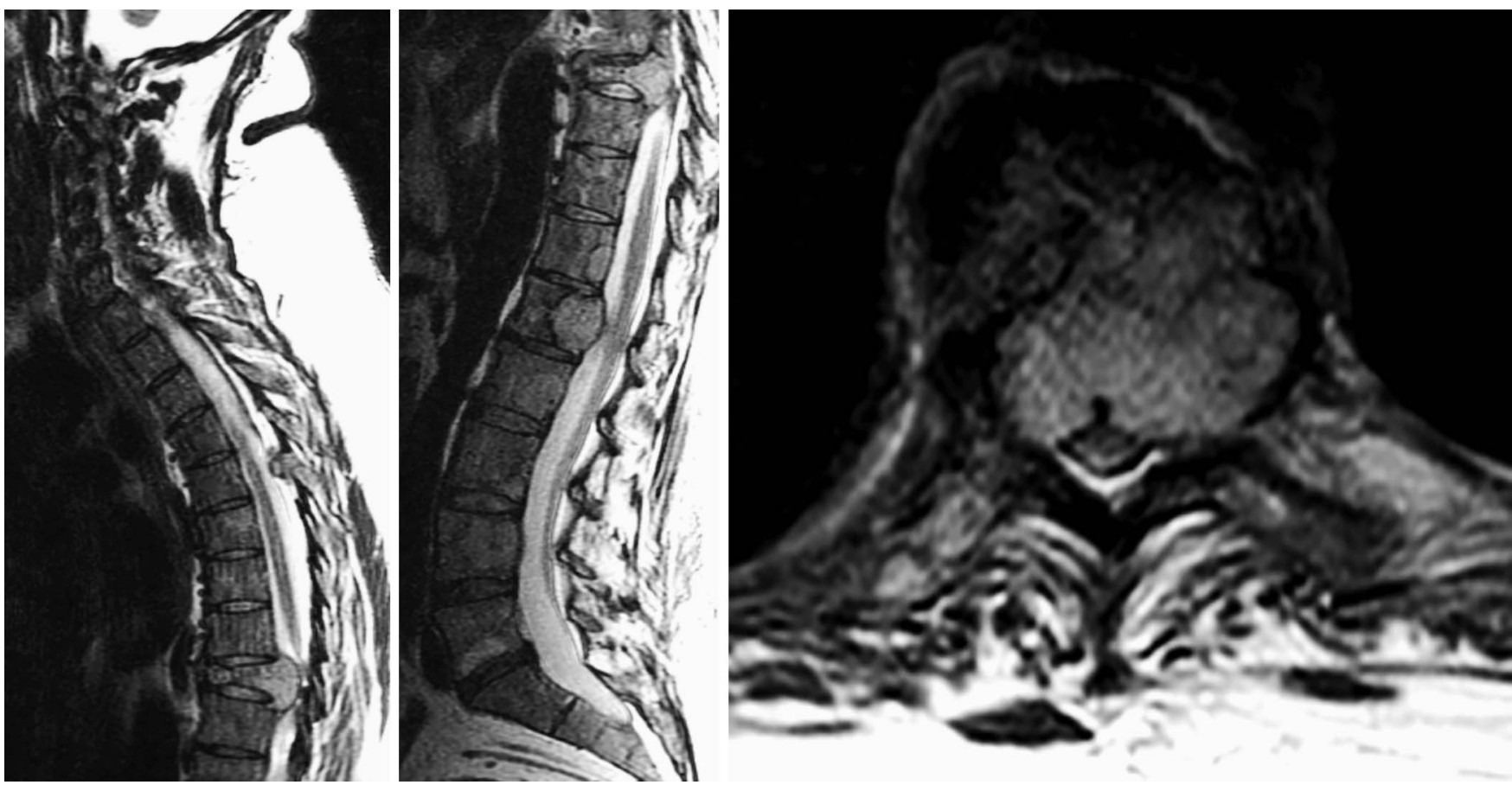

Figure 1. Preoperative T2 magnetic resonance imaging (MRI) complete spine images showing extensive metastatic disease of the spine. (Left) Sagittal T2 MRI of the upper spine showing pathologic compression fracture of the T9 vertebral body with retropulsion of the posterior vertebral body obliterating the cerebrospinal fluid space. (Middle) Sagittal T2 MRI of the lower spine showing extensive metastatic disease throughout the lumbar spine. (Right) Axial T2 MRI at the level of the T9 vertebral body.

weak, although she was able to ambulate normally. She denied lower extremity symptoms, saddle anesthesia, and changes in urination or defecation. Physical exam was normal except for tenderness to palpation along the lower thoracic spine. She reported no overt signs of catecholamine excess such as tremors, headaches, visual symptoms, palpitations, weight loss, and diaphoresis. Preoperatively, both her blood pressure and pulse were within normal limits and she was not on any antihypertensive medications. On imaging with computed tomography (CT), magnetic resonance imaging (MRI), and fluorodeoxyglucose positron emission tomography, she was found to have multilevel lytic lesions throughout the cervical, thoracic, and lumbar spine at $\mathrm{C} 1, \mathrm{C} 4-\mathrm{C} 7$, L1-L3, as well as involvement of the right mandibular condyle and clavicle. She had compression fractures of the $\mathrm{C} 3$ and $\mathrm{T} 9$ vertebral bodies both with greater than $80 \%$ loss of height, and retropulsion causing moderate-to-severe spinal canal stenosis. Spinal canal extension was present at T4, T5, T9, L1, and L4, and most severe at T9, which was considered to be the symptomatic level (Figure 1).

On the day after admission, percutaneous biopsy was performed of the L1 soft tissue lesion, and this confirmed metastatic PGL. Histologic sections of the biopsy specimen contained abundant groups of nested cells characterized by mild anisonucleosis, stippled nuclear chromatin, and abundant pale eosinophilic and slightly granular cytoplasm. Mitotic figures were seen at 7 in 10 high-power fields (Figure 2A). Immunohistochemical stains for S100, synaptophysin, chromogranin, and succinate dehydrogenase subunit B (SDHB) were performed. Tumor cells stained positive for synaptophysin (Figure 2B) and chromogranin. The S100 stain highlighted a fragmented network of sustenacular cells surrounding the neoplastic cells (Figure 2C). SDHB showed intracytoplasmic granular positivity within vascular endothelium but complete loss of staining in the tumor cells (Figure 2D), indicative of an underlying $S D H x$ gene mutation.

Given clinical concern for spinal instability and epidural cord compression, the patient underwent lateral extracavitary approach for partial corpectomy and laminectomy for tumor resection at $\mathrm{T} 9$ and posterior instrumented fusion of T7-T11. The patient tolerated the procedure well with $400 \mathrm{~mL}$ of blood loss and no hypertensive complications. In consultation with anesthesiology, preoperative alpha blockade was not performed. ${ }^{15}$ Grossly, the tumor appeared as fragments of red-brown soft tumor mixed with blood and trabecular bone fragments. Histologic and immunohistochemical analysis was consistent with recent biopsy. A postoperative $\mathrm{x}$-ray was obtained to confirm ade- 


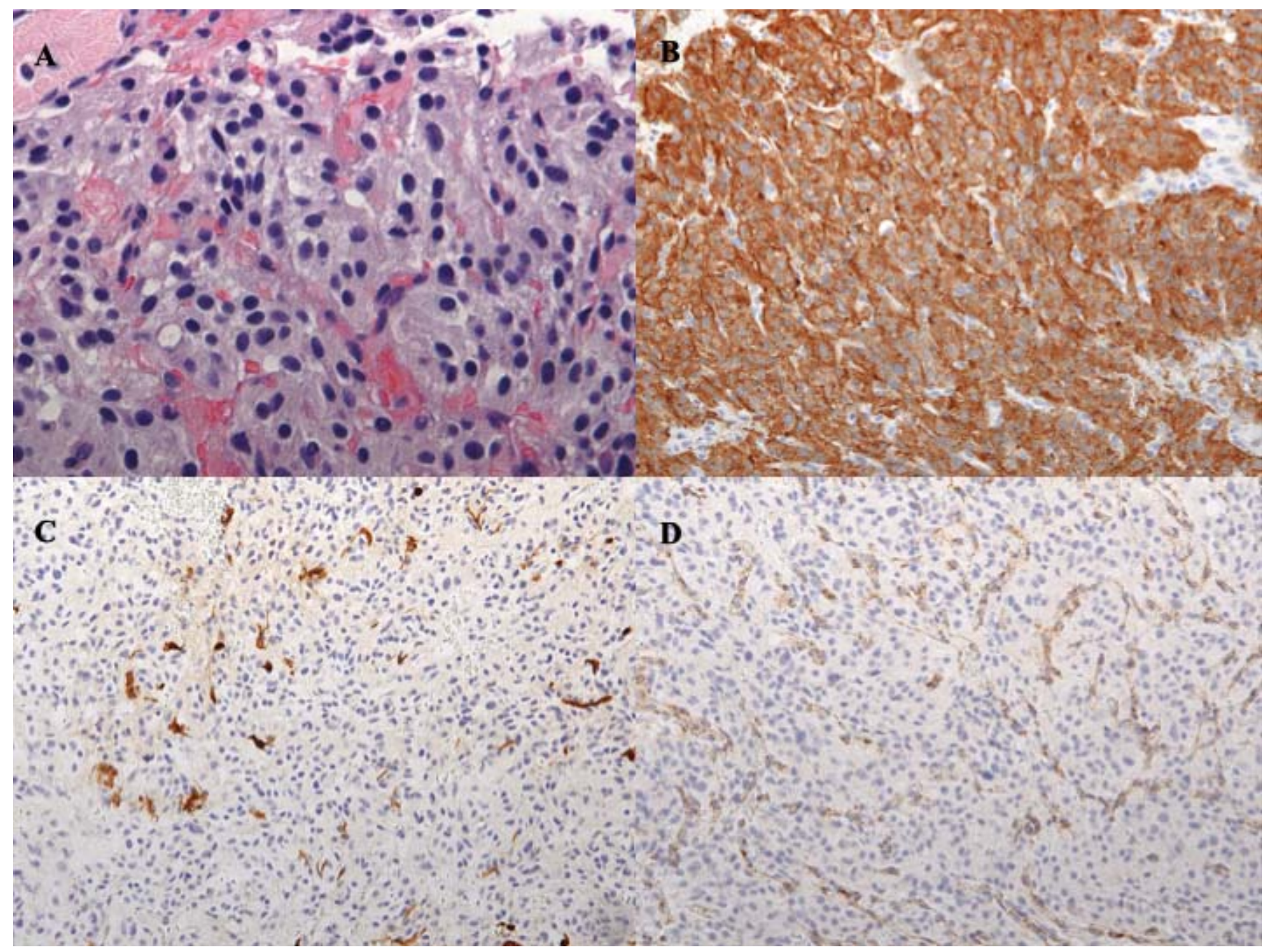

Figure 2. Histologic and immunohistochemical sections of metastatic paraganglioma biopsy specimen. (A) Hematoxylin-eosin stain of metastatic paraganglioma (×60). Histologic sections of the biopsy specimen showing an epithelioid proliferation of cells with nested architecture ("Zellballen") with a delicate tumor vascular network between nests. The epithelioid cells show round to ovoid nuclei, minimal nuclear pleomorphism, and stippled chromatin with abundant granular amphophilic cytoplasm. Mitotic figures are seen at 7 in 10 high-power fields. (B) Immunohistochemical stain for synaptophysin showing positive granular cytoplasmic staining in tumor cells $(\times 20)$. (C) Immunohistochemical stain for S-100 highlighting fragmented network of sustenacular cells surrounding tumor cells ( $\times 20)$. (D) Immunohistochemical stain for succinate dehydrogenase subunit B (SDHB) showing absence of SDHB among tumor cells, while maintaining positive internal control within vascular endothelium $(\times 20)$.

quate positioning of hardware (Figure 3). Patient was discharged on postoperative day 5 with a thoracic lumbosacral orthosis brace and cervical collar. Although no family history of pheochromocytoma or PGL was obtained on review, germline testing was recommended with particular concern for $S D H B$ mutation given negative SDHB immunohistochemistry and the aggressive metastatic nature of the PGL. The patient was found to have a pathogenic $S D H B$ deletion (c.166_170delCCTCA) which resulted in a frame shift and protein truncation (p.P56Yfs*5). Genetic testing was arranged for at-risk relatives, where several affected individuals were identified.

At 18 months after surgery the patient's metastatic disease is stable (Figure 4). She has received 10 sessions of radiation to the spine and 8 cycles of chemotherapy with cyclophosphamide, dacarbazine, and vincristine. Additionally, she has been receiving monthly octreotide and denosumab injections to promote disease stabilization and prevent further bone loss, respectively. Given the patient's advanced disease, additional screening beyond standard response surveillance was not pursued.

\section{RESULTS AND DISCUSSION}

Metastatic extra-adrenal PGL to the spine is a rare phenomenon with limited case reports and 2 small case series described in the English literature (Table 1). ${ }^{4,10,11}$ Here, we present what is, to our knowledge, the fourth case report of metastatic 


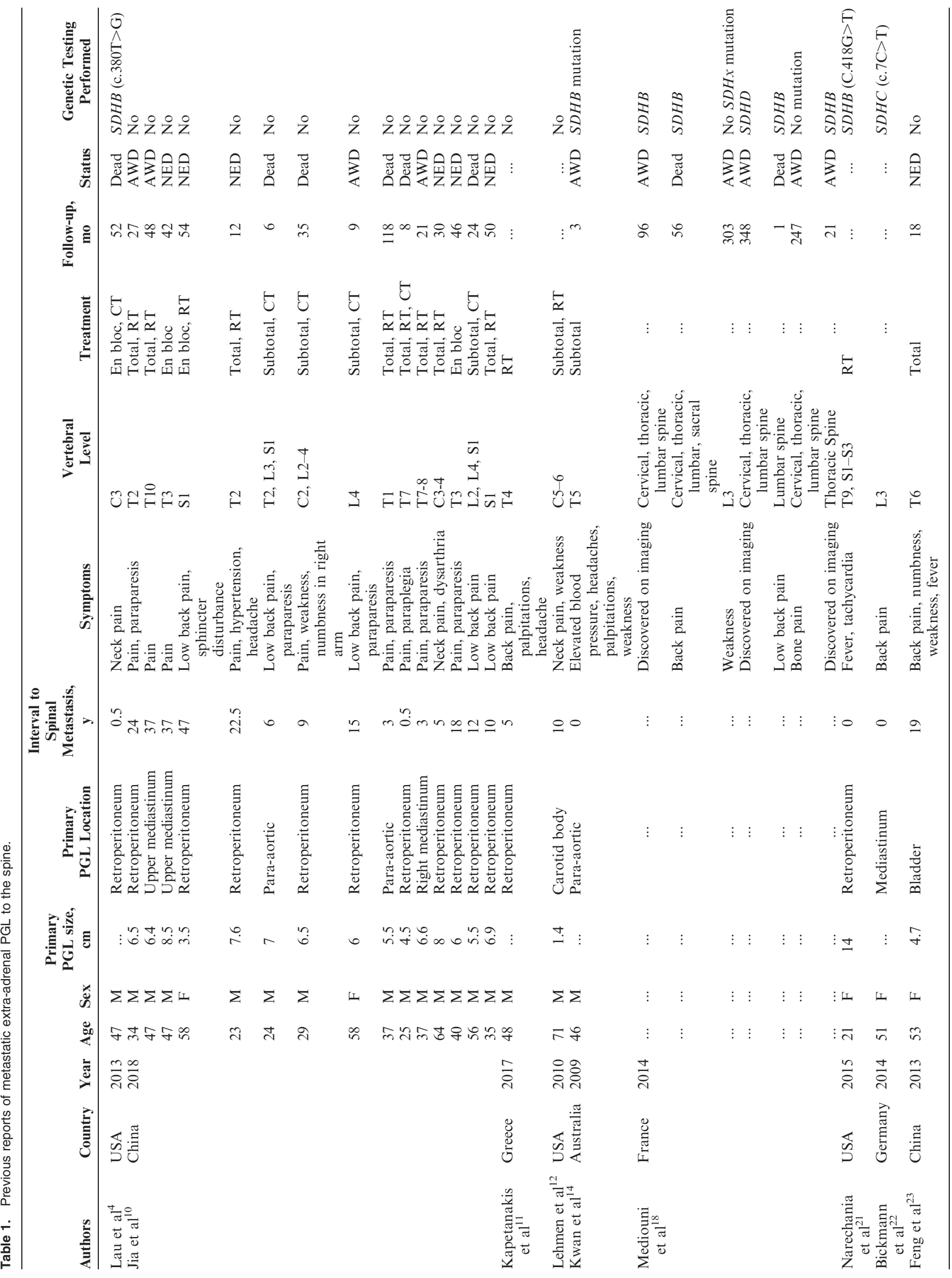




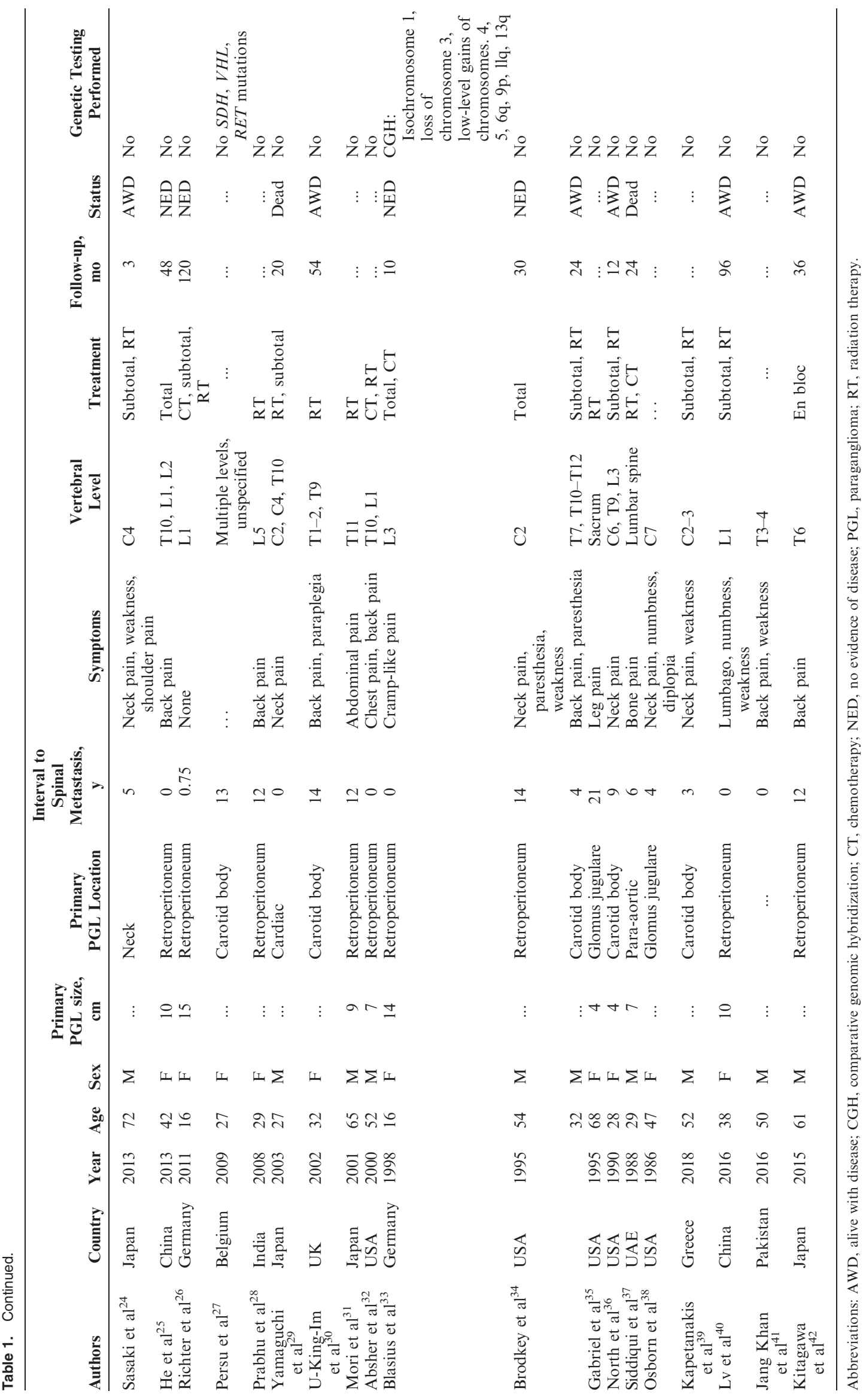




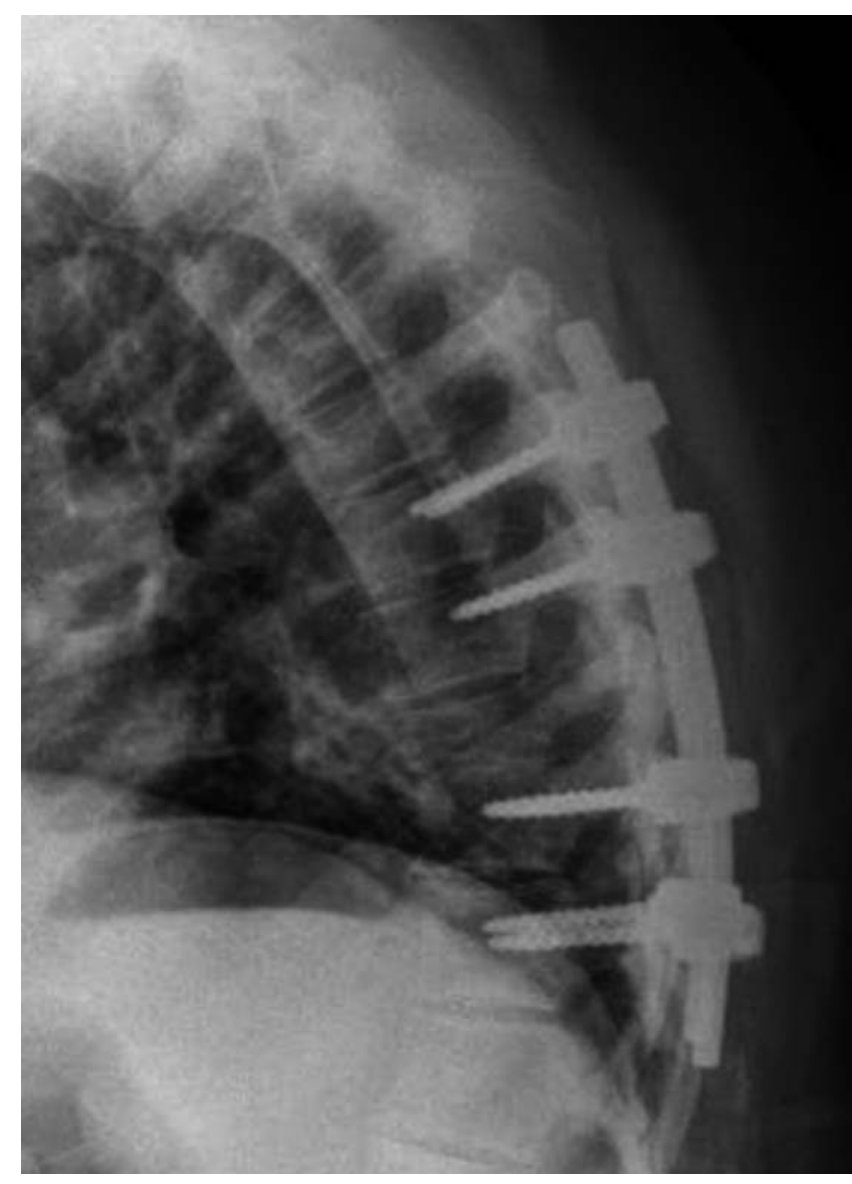

Figure 3. Postoperative sagittal x-ray of the spine showing instrumentation.

PGL to the spine found to have a mutation of an $S D H$ subunit, (SDHA, SDHB, SDHC, SDHD) or assembly factor $(S D H-A F 2){ }^{4}$ While there are limited data available on the metastatic tendencies of extra-adrenal PGL, studies looking at both metastatic pheochromocytomas and extra-adrenal PGLs have found bone to be the most common site of metastasis followed by liver and lung. ${ }^{16-19}$ The spine is the most common site of bone metastasis. ${ }^{16}$ In this case our patient had an interval of 27 years between total resection of her primary tumor and spinal metastasis. This extended interval is consistent with previous case reports as shown in Table 1. ${ }^{10,12,20}$

Genetic testing is recommended for all patients with PGLs and their first-degree relatives., ${ }^{3,43}$ Over the past several years it has been shown that $20 \%-$ $40 \%$ of patients with pheochromocytoma and extraadrenal PGL have a germline mutation in $S D H x$, $N F 1, V H L$, or RET. ${ }^{44-46}$ While mutations in NF1, $V H L$, and $R E T$ genes cause well-characterized hereditary syndromes, the association between SDHX mutations and PGLs was more recently

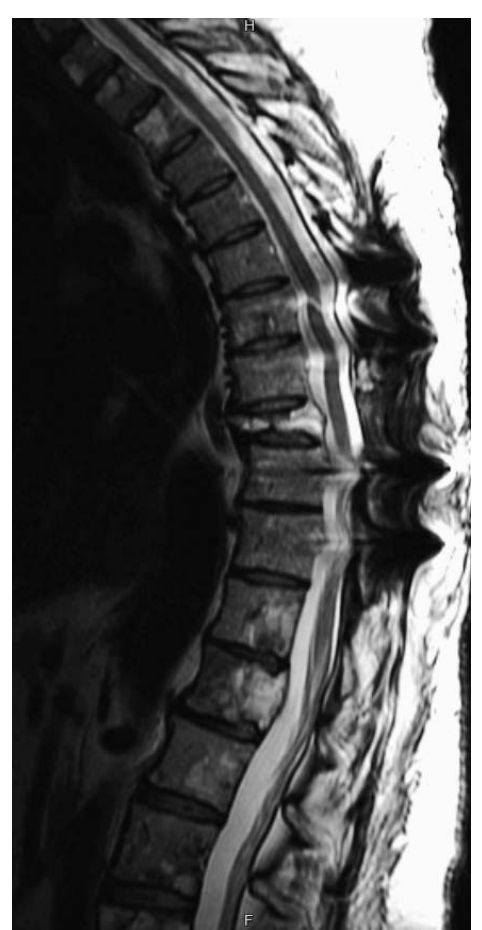

Figure 4. Post-operative T2 magnetic resonance imaging of thoracic spine at 1.5 years showing stable disease.

elucidated. ${ }^{6,47-49} \mathrm{SDH}$ is a mitochondrial enzyme complex that plays a role in both the tricarboxylic acid cycle and in the electron transport chain. $S D H$ genes function as classical tumor suppressor genes where somatic loss of heterozygosity of the wildtype allele is observed in tumors. ${ }^{6,50}$ While the precise pathogenic mechanism of $S D H$-mutationdependent tumor formation is incompletely understood, the leading theory revolves around the role of succinate as an oncometabolite. ${ }^{51}$ Specifically, it is thought that disruption of SDH complex function, which leads to an accumulation of succinate, increases the risk of cancer because succinate accumulation competitively inhibits $\alpha$-ketoglutarate dependent enzymes such as prolyl hydroxylases and histone demethylases. Inhibition of hypoxia-inducible factor prolyl hydroxylases leads to the stabilization of hypoxia-inducible factors, which normally promote angiogenesis and cell survival in hypoxic conditions. Inhibition of histone demethylases causes a cell to adopt a hypermethylator phenotype that is thought to silence genes associated with neuroendocrine differentiation. ${ }^{52-54}$ SDHx mutations are the most frequent hereditary cause of extra-adrenal PGLs with autosomal-dominant mutations in $S D H D$ and $S D H B$ being the most common. $^{6,49}$ Immunohistochemical and genetic testing all PGLs for $S D H x$ mutation, and in 
particular for $S D H B$ mutation, is critically important as $30 \%-70 \%$ of metastatic PGLs have been found to have an $S D H B$ germline mutation. ${ }^{48,55,56}$ Thus, while there are no definite histological markers of metastatic PGL, $S D H B$ mutation is a strong independent predictor in addition to primary tumor size $>5 \mathrm{~cm}$ and extra-adrenal location. ${ }^{8}$ Interestingly, although our patient's primary tumor was reportedly $>8 \mathrm{~cm}$ in size and extra-adrenal in location she was not screened for SDHB mutation prior to receiving care at our institution for her spinal metastasis.

Whole-body scanning for detection of metastatic PGL is recommended at the time of primary tumor detection. $^{3}$ Metastatic disease can be detected through a combination of anatomical (CT, MRI) and scintigraphic imaging techniques (fluorodeoxyglucose positron emission tomography, metaiodobenzylguanidine scintigraphy, and more recently somatostatin receptor scintigraphy with $68 \mathrm{Ga}-\mathrm{DO}-$ TATATE). ${ }^{57,58}$ Fluorodeoxyglucose positron emission tomography is currently the preferred imaging technique for detecting metastatic disease although several recent studies suggest that 68Ga-DOTATATE may have greater sensitivity particularly in the context of SDH-related disease. 3,59,60 Long-term imaging follow-up in addition to annual clinical evaluation and laboratory testing is required for all patients with PGLs as approximately $50 \%$ of metastatic PGLs present metachronously and in particular for patients with SDHx mutations, who have an increased risk for metastatic disease. ${ }^{19}$ At this time no clear guidelines exist regarding the optimal frequency of imaging for PGL patients. ${ }^{3}$ In terms of laboratory testing, the Endocrine Society recommends lifelong annual testing of plasma or urine metanephrine levels to assess for recurrent or persistent disease. $^{3}$

Treatment of metastatic PGL of the spine involves a combination of surgery, radiation therapy, and chemotherapy. As with other metastatic tumors of the spine the primary goals of surgery are management of spinal instability caused by lytic lesions, and decompression of the spinal cord secondary to any epidural tumor. ${ }^{61}$ Surgical resection of the primary tumor has been shown to improve overall survival in cases of synchronous metastatic PGL. ${ }^{62}$ Radiation therapy is the primary of method of local control for metastatic disease that is unresectable. Chemotherapy is reserved for widely metastatic disease with cyclophosphamide, dacarbazine, and vincristine being the preferred regimen. ${ }^{63}$ Overall, metastatic PGL is difficult to treat with 5-year overall survival at approximately $60 \%{ }^{61}$

In conclusion, metastasis to the spine is a rare but important complication in patients with PGL that can lead to significant pain and disability. Genetic testing is recommended for all patients with PGLs. Patients with $S D H x$ mutations are more likely to develop metastatic disease and $S D H x$ mutation status is the current best predictor of metastatic PGL. SDHX mutation carriers must have frequent long-term imaging surveillance performed given the potential for metastasis several years to decades after primary resection. Neurosurgical management of metastatic PGL of the spine involves correcting spinal instability and alleviating epidural cord compression. When caring for patient with metastatic PGL of the spine, genetic testing for patients and their families should be considered.

\section{REFERENCES}

1. Simpson LN, Hughes BD, Karikari IO, et al. Catecholamine-secreting paraganglioma of the thoracic spinal column: report of an unusual case and review of the literature. Neurosurgery. 2012;70(4):E1049-1052; discussion E1052.

2. Baysal BE. Hereditary paraganglioma targets diverse paraganglia. J Med Genet. 2002;39(9):617-622.

3. Lenders JW, Duh QY, Eisenhofer G, et al. Pheochromocytoma and paraganglioma: an Endocrine Society clinical practice guideline. J Clin Endocrinol Metab. 2014;99(6):19151942.

4. Lau D, La Marca F, Camelo-Piragua S, Park P. Metastatic paraganglioma of the spine: case report and review of the literature. Clin Neurol Neurosurg. 2013;115(9):1571-1574.

5. Erickson D, Kudva YC, Ebersold MJ, et al. Benign paragangliomas: clinical presentation and treatment outcomes in 236 patients. J Clin Endocrinol Metab. 2001;86(11):5210 5216.

6. Welander J, Soderkvist P, Gimm O. Genetics and clinical characteristics of hereditary pheochromocytomas and paragangliomas. Endocr Relat Cancer. 2011;18(6):R253-276.

7. Al-Harthy M, Al-Harthy S, Al-Otieschan A, Velagapudi S, Alzahrani AS. Comparison of pheochromocytomas and abdominal and pelvic paragangliomas with head and neck paragangliomas. Endocr Pract. 2009;15(3):194-202.

8. Plouin PF, Fitzgerald $\mathrm{P}$, Rich $\mathrm{T}$, et al. Metastatic pheochromocytoma and paraganglioma: focus on therapeutics. Horm Metab Res. 2012;44(5):390-399.

9. Laird AM, Gauger PG, Doherty GM, Miller BS. Paraganglioma: not just an extra-adrenal pheochromocytoma. Langenbecks Arch Surg. 2012;397(2):247-253.

10. Jia Q, Yin H, Yang J, et al. Treatment and outcome of metastatic paraganglioma of the spine. Eur Spine $J$. 2018;27(4):859-867.

11. Kapetanakis S, Chourmouzi D, Gkasdaris G, Katsaridis V, Eleftheriadis E, Givissis P. Functional extra-adrenal 
paraganglioma of the retroperitoneum giving thoracolumbar spine metastases after a five-year disease-free follow-up: a rare malignant condition with challenging management. Pan $\mathrm{Afr}$ Med J. 2017;28:94.

12. Lehmen JA, Babbel DM, Mikhitarian K, Choma TJ. Paraganglioma presenting as metastatic lesion in a cervical vertebra: a case report and review of the literature. Spine (Phila $P a$ 1976). 2010;35(5):E152-154.

13. Hamilton MA, Tait D. Metastatic paraganglioma causing spinal cord compression. Br J Radiol. 2000;73(872):901-904.

14. Kwan RB, Erasmus AM, Hunn AW, et al. Pre-operative embolisation of metastatic paraganglioma of the thoracic spine. J Clin Neurosci. 2010;17(3):394-396.

15. Isaacs $M$, Lee $P$. Preoperative alpha-blockade in phaeochromocytoma and paraganglioma: is it always necessary? Clin Endocrinol (Oxf). 2017;86(3):309-314.

16. Zelinka T, Timmers HJ, Kozupa A, et al. Role of positron emission tomography and bone scintigraphy in the evaluation of bone involvement in metastatic pheochromocytoma and paraganglioma: specific implications for succinate dehydrogenase enzyme subunit B gene mutations. Endocr Relat Cancer. 2008;15(1):311-323.

17. Chrisoulidou A, Kaltsas G, Ilias I, Grossman AB. The diagnosis and management of malignant phaeochromocytoma and paraganglioma. Endocr Relat Cancer. 2007;14(3):569-585.

18. Mediouni A, Ammari S, Wassef M, et al. Malignant head/neck paragangliomas. Comparative study. Eur Ann Otorhinolaryngol Head Neck Dis. 2014;131(3):159-166.

19. Ayala-Ramirez M, Palmer JL, Hofmann MC, et al. Bone metastases and skeletal-related events in patients with malignant pheochromocytoma and sympathetic paraganglioma. $J$ Clin Endocrinol Metab. 2013;98(4):1492-1497.

20. Ayala-Ramirez M, Feng L, Johnson MM, et al. Clinical risk factors for malignancy and overall survival in patients with pheochromocytomas and sympathetic paragangliomas: primary tumor size and primary tumor location as prognostic indicators. J Clin Endocrinol Metab. 2011;96(3):717-725.

21. Narechania S, Bath A, Ghassemi L, et al. Paraganglioma presenting as postpartum fever of unknown origin. Case Rep Endocrinol. 2015;2015:864719.

22. Bickmann JK, Sollfrank S, Schad A, et al. Phenotypic variability and risk of malignancy in SDHC-linked paragangliomas: lessons from three unrelated cases with an identical germline mutation (p.Arg133*). J Clin Endocrinol Metab. 2014;99(3):E489-496.

23. Feng N, Li X, Gao HD, Liu ZL, Shi LJ, Liu WZ. Urinary bladder malignant paraganglioma with vertebral metastasis: a case report with literature review. Chin J Cancer. 2013;32(11):624-628.

24. Sasaki K, Inose H, Kawabata S, et al. Combined surgical and radiosurgical treatment for a symptomatic cervical metastasis in a case of malignant paraganglioma: a case report. BMC Res Notes. 2013;6:494.

25. He J, Wang X, Zheng W, Zhao Y. Retroperitoneal paraganglioma with metastasis to the abdominal vertebra: a case report. Diagn Pathol. 2013;8:52.

26. Richter A, Halm HF, Lerner T, Liljenqvist UR, Quante M. Long-term follow-up after en bloc resection and reconstruction of a solitary paraganglioma metastasis in the first lumbar vertebral body: a case report. J Med Case Rep. 2011;5:45.

27. Persu A, Amyere M, Gutierrez-Roelens I, et al. Rare presentation of familial paraganglioma without evidence of mutation in the SDH, RET and VHL genes: towards further genetic heterogeneity. J Hypertens. 2009;27(1):76-82.

28. Prabhu S, Jacob JJ, Thomas N, Oommen R. Visual vignette. Solitary sacral metastasis from a malignant paraganglioma. Endocr Pract. 2008;14(1):131.

29. Yamaguchi S, Hida K, Nakamura N, Seki T, Iwasaki Y. Multiple vertebral metastases from malignant cardiac pheochromocytoma-case report. Neurol Med Chir (Tokyo). 2003;43(7):352-355.

30. U-King-Im JM, Carroll TA, Morris K. Vertebral metastatic chemodectoma: imaging and therapeutic octreotide. Case report. J Neurosurg. 2002;97(1 Suppl):106-109.

31. Mori S, Okura T, Kitami Y, et al. A case of metastatic extra-adrenal pheochromocytoma 12 years after surgery. Hypertens Res. 2002;25(1):141-144.

32. Absher KJ, Witte DA, Truong LD, Ramzy I, Mody DR, Ostrowski ML. Aspiration biopsy of osseous metastasis of retroperitoneal paraganglioma. Report of a case with cytologic features and differential diagnostic considerations. Acta Cytol. 2001;45(2):249-253.

33. Blasius S, Brinkschmidt C, Poremba C, et al. Metastatic retroperitoneal paraganglioma in a 16-year-old girl. Case report, molecular pathological and cytogenetic findings. Pathol Res Pract. 1998;194(6):439-444.

34. Brodkey JA, Brodkey JS, Watridge CB. Metastatic paraganglioma causing spinal cord compression. Spine (Phila Pa 1976). 1995;20(3):367-372.

35. Gabriel EM, Sampson JH, Dodd LG, Turner DA. Glomus jugulare tumor metastatic to the sacrum after highdose radiation therapy: case report. Neurosurgery. 1995;37(5):1001-1005.

36. North CA, Zinreich ES, Christensen WN, North RB. Multiple spinal metastases from paraganglioma. Cancer. 1990;66(10):2224-2228.

37. Siddiqui MZ, Von Eyben FE, Spanos G. High-voltage irradiation and combination chemotherapy for malignant pheochromocytoma. Cancer. 1988;62(4):686-690.

38. Osborn RE, Mojtahedi S. Paraganglioma metastatic to the cervical spine. Comput Radiol. 1986;10(4):167-170.

39. Kapetanakis S, Chourmouzi D, Gkasdaris G, Katsaridis V, Eleftheriadis E, Givissis P. A rare case of spinal cord compression due to cervical spine metastases from paraganglioma of the jugular foramen-how should it be treated? J Surg Case Rep. 2018;2018(2):rjy005.

40. Lv G, Lu L, Dai Z. Paragangliomas of the spine. Turk Neurosurg. 2017;27(3):401-407.

41. Jang Khan NA, Ullah S, Siddiqui HU, Karim A. spinal cord compression by metastatic thoracic spine paraganglioma. J Ayub Med Coll Abbottabad. 2016;28(3):617-619.

42. Kitagawa R, Murakami H, Kato S, Nakada M, Demura $\mathrm{S}$, Tsuchiya $\mathrm{H}$. En bloc resection and reconstruction using a frozen tumor-bearing bone for metastases of the spine and cranium from retroperitoneal paraganglioma. World Neurosurg. 2016;90:698.e691-698.e695.

43. Cavenagh T, Patel J, Nakhla N, et al. Succinate dehydrogenase mutations: paraganglioma imaging and at-risk population screening. Clin Radiol. 2019;74(3):169-177.

44. Buffet A, Venisse A, Nau V, et al. A decade (2001-2010) of genetic testing for pheochromocytoma and paraganglioma. Horm Metab Res. 2012;44(5):359-366.

45. Neumann HP, Bausch B, McWhinney SR, et al. Germ- 
line mutations in nonsyndromic pheochromocytoma. $N$ Engl $J$ Med. 2002;346(19):1459-1466.

46. Fishbein L, Merrill S, Fraker DL, Cohen DL, Nathanson KL. Inherited mutations in pheochromocytoma and paraganglioma: why all patients should be offered genetic testing. Ann Surg Oncol. 2013;20(5):1444-1450.

47. Baysal BE, Ferrell RE, Willett-Brozick JE, et al. Mutations in SDHD, a mitochondrial complex II gene, in hereditary paraganglioma. Science. 2000;287(5454):848-851.

48. Neumann HP, Pawlu C, Peczkowska M, et al. Distinct clinical features of paraganglioma syndromes associated with SDHB and SDHD gene mutations. JAMA. 2004;292(8):943951.

49. van Nederveen FH, Gaal J, Favier J, et al. An immunohistochemical procedure to detect patients with paraganglioma and phaeochromocytoma with germline SDHB, SDHC, or SDHD gene mutations: a retrospective and prospective analysis. Lancet Oncol. 2009;10(8):764-771.

50. Fishbein L, Nathanson KL. Pheochromocytoma and paraganglioma: understanding the complexities of the genetic background. Cancer Genet. 2012;205(1-2):1-11.

51. Sajnani K, Islam F, Smith RA, Gopalan V, Lam AK. Genetic alterations in Krebs cycle and its impact on cancer pathogenesis. Biochimie. 2017;135:164-172.

52. Letouze E, Martinelli C, Loriot C, et al. SDH mutations establish a hypermethylator phenotype in paraganglioma. Cancer Cell. 2013;23(6):739-752.

53. Tretter L, Patocs A, Chinopoulos C. Succinate, an intermediate in metabolism, signal transduction, ROS, hypoxia, and tumorigenesis. Biochim Biophys Acta. 2016;1857(8):10861101 .

54. Fliedner SM, Shankavaram U, Marzouca G, et al. Hypoxia-inducible factor 2alpha mutation-related paragangliomas classify as discrete pseudohypoxic subcluster. Neoplasia. 2016;18(9):567-576.

55. King KS, Prodanov T, Kantorovich V, et al. Metastatic pheochromocytoma/paraganglioma related to primary tumor development in childhood or adolescence: significant link to SDHB mutations. J Clin Oncol. 2011;29(31):4137-4142.

56. Gimenez-Roqueplo AP, Favier J, Rustin P, et al. Mutations in the SDHB gene are associated with extra-adrenal and/or malignant phaeochromocytomas. Cancer Res. 2003;63(17):5615-5621.

57. Gimenez-Roqueplo AP, Caumont-Prim A, Houzard C, et al. Imaging work-up for screening of paraganglioma and pheochromocytoma in SDHx mutation carriers: a multicenter prospective study from the PGL.EVA Investigators. $J$ Clin Endocrinol Metab. 2013;98(1):E162-173.

58. Lepoutre-Lussey C, Caramella C, Bidault F, et al. Screening in asymptomatic SDHx mutation carriers: added value of (1)(8)F-FDG PET/CT at initial diagnosis and 1-year follow-up. Eur J Nucl Med Mol Imaging. 2015;42(6):868-876.

59. Timmers HJ, Kozupa A, Chen CC, et al. Superiority of fluorodeoxyglucose positron emission tomography to other functional imaging techniques in the evaluation of metastatic SDHB-associated pheochromocytoma and paraganglioma. $J$ Clin Oncol. 2007;25(16):2262-2269.

60. Janssen I, Blanchet EM, Adams K, et al. Superiority of [68ga]-dotatate pet/ct to other Functional Imaging Modalities in the Localization of SDHB-associated metastatic pheochromocytoma and paraganglioma. Clin Cancer Res. 2015;21(17):38883895.

61. Jimenez P, Tatsui C, Jessop A, Thosani S, Jimenez C. Treatment for malignant pheochromocytomas and paragangliomas: 5 years of progress. Curr Oncol Rep. 2017;19(12):83.

62. Roman-Gonzalez A, Zhou S, Ayala-Ramirez M, et al. Impact of surgical resection of the primary tumor on overall survival in patients with metastatic pheochromocytoma or sympathetic paraganglioma. Ann Surg. 2018;268(1):172-178.

63. Fliedner SM, Lehnert H, Pacak K. Metastatic paraganglioma. Semin Oncol. 2010;37(6):627-637.

Disclosures and COI: None declared. This research did not receive any specific grant from funding agencies in the public, commercial, or notfor-profit sectors. Patient's written informed consent for publication was obtained.

Corresponding Author: Atman M. Desai, MD, Department of Neurosurgery, Stanford University School of Medicine, 300 Pasteur Dr, R200, Stanford, CA, 94305. Phone: (650) 495-6971; Fax: (408) 885-5686; Email: atman@stanford.edu.

Published 11 February 2021

This manuscript is generously published free of charge by ISASS, the International Society for the Advancement of Spine Surgery. Copyright (C) 2020 ISASS. To see more or order reprints or permissions, see http://ijssurgery.com. 